\title{
INPUT COUPLER FOR ERL INJECTOR CAVITIES*
}

\author{
V. Veshcherevich ${ }^{\dagger}$, I. Bazarov, S. Belomestnykh, M. Liepe, H. Padamsee, and V. Shemelin \\ Laboratory for Elementary-Particle Physics, Cornell University, Ithaca, NY 14853, USA
}

\section{Abstract}

A conceptual design of the input coupler for superconducting injector cavities of Cornell/JLab ERL project is presented. The injector cavities are two-cell structures operating at $1300 \mathrm{MHz}$ in $\mathrm{CW}$ mode. The coupler has a symmetric design to accommodate requirements for small transverse kick, high RF power delivery to the cavity, and high input coupling value. Therefore it consists of two identical antenna type couplers symmetrically attached to a beam pipe of the cavity. Each coupler delivers $50 \mathrm{~kW}$ of $\mathrm{CW}$ RF power to the beam. The coupler has a variable coupling. $Q_{\text {ext }}$ should be varied from $4.6 \times 10^{4}$ to $4.1 \times 10^{5}$. The symmetric design of the coupler dramatically reduces the transverse kick, a critical requirement for the ERL project. Estimates of the influence of coupler induced fields on beam dynamics are given.

\section{INTRODUCTION}

The project of Energy Recovery Linac (ERL) - a challenging ultra-high brightness X-ray source of a new generation-is in the R\&D stage at Cornell University and Jefferson Laboratory [1], [2], [3]. It should be a CW $100 \mathrm{MeV}$ machine with high average current (100 mA). Superconducting $1300 \mathrm{MHz}$ RF structures will be used in the main linac and injector of this project. A goal of the ERL project is achieving a $2 \mu \mathrm{m}$ emittance for a bunch charge $q$ of $77 \mathrm{pC}$ and $0.2 \mu \mathrm{m}$ for $8 \mathrm{pC}$ at the undulator location. This implies emittances of about $1 \mu \mathrm{m}$ and $0.1 \mu \mathrm{m}$ in the injector for the two different bunch charges.

A high brightness injector [4] is a key element of this machine. It includes a $500 \mathrm{keV}$ DC photoemission electron gun, a conventional buncher, and five two-cell superconducting RF cavities. The injector cavities should accelerate the beam to a nominal energy of $5.5 \mathrm{MeV}$ ( $1 \mathrm{MeV}$ per cavity) with minimal emittance dilution. It requires delivering $500 \mathrm{~kW}$ power to the beam $(100 \mathrm{~kW}$ for each cavity). Operation with acceleration to about 15.5 MeV (3 MeV per cavity) is also planned at a reduced average current $(33 \mathrm{~mA})$, limited by the total RF power available. All five two-cell cavities will be mounted in a single cryomodule [5].

\section{REQUIREMENTS TO THE INJECTOR CAVITY COUPLER}

The parameters of the injector cavities are summarized in Table 1. The injector cavity coupler has to deliver

\footnotetext{
* Supported by Cornell University.
}

$\dagger$ vgv@lepp.cornell.edu
Table 1: Parameters of the injector cavities

$\begin{array}{lc}\text { Energy of electrons, } E & 0.5 \text { to } 5.5(15.5) \mathrm{MeV} \\ \text { Beam current, } I_{0} & 100(33) \mathrm{mA} \\ \text { Frequency, } f & 1300 \mathrm{MHz} \\ \text { Number of cells per cavity, } N_{\mathrm{c}} & 2 \\ Q_{0} & \geq 5 \times 10^{9} \\ Q_{\text {ext }}, \text { nominal } & 4.6 \times 10^{4} \\ Q_{\text {ext }}, \text { range } & 4.6 \times 10^{4} \text { to } 4.1 \times 10^{5} \\ R / Q & 218 \mathrm{Ohm} \\ \text { Cavity voltage, } V & 1(3) \mathrm{MV} \\ \text { RF power per cavity, } P & 150 \mathrm{~kW}\end{array}$

$100 \mathrm{~kW}$ of RF power to the beam and provide matching conditions for a cavity gap voltage of 1 through $3 \mathrm{MV}$ and corresponding beam currents of 100 through $33 \mathrm{~mA}$. Thus the external $Q$ factor range is $4.6 \times 10^{4}$ to $4.1 \times 10^{5}$ or a factor of 9. This coupler should be designed to withstand an RF power up to $150 \mathrm{~kW} \mathrm{CW}$ in traveling wave (TW), the installed RF power per cavity.

The main design challenges to RF power coupler of the injector cavity are:

- High average RF power (up to $150 \mathrm{~kW}$ TW)

- Very strong coupling $\left(Q_{\mathrm{ext}}=4.6 \times 10^{4}\right)$

- Wide range of variable coupling (factor of 9)

- Minimizing transverse kick to the beam to avoid emittance growth

- Multipacting-free (or almost multipacting-free) design

\section{COUPLER DESIGN}

We considered different options of the coupler design [6]. Finally, we chose a twin coaxial coupler [7], [8]. It consists of two identical antenna type couplers symmetrically attached to a beam pipe of the cavity (see Fig. 1). With this approach only a half of the full RF

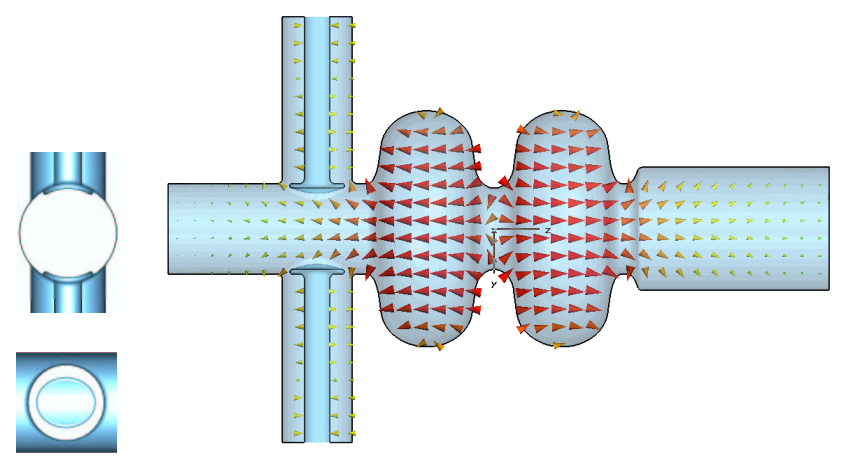

Figure 1: Input coupler in the injector cavity. 
power goes through a single coupler and twice as less coupling is necessary $\left(Q_{\text {ext }}=9.2 \times 10^{4}\right)$. Another excellent feature is a good transverse field symmetry, which is very important for the ERL requirements-no more than $10 \%$ of the emittance growth due to injector cavities.

As individual couplers we decided to use the TTF III couplers [9] modified to meet our requirements. It is rather natural because we plan to use TESLA cavities and cryostats in the main linac structure. We took into account some of the B. Dwersteg's advices given in [10].

The cold part of the original coupler was completely redesigned. Instead of a $40 \mathrm{~mm} 70$ ' $\Omega$ coaxial line, a $62 \mathrm{~mm} 60$ ' $\Omega$ line was chosen for getting a stronger coupling and better handling the high power. It is also multipacting-free in the full power range [7]. The coupler has a larger profiled antenna tip to provide a strong coupling. The travel range of the antenna was increased to $15 \mathrm{~mm}$ for getting the required coupling variation (see Fig. 2). In the cold window a bigger ceramic cylinder is used (similar to the one used in the warm window but with a reduced height). The weakest points of the TTF III coupler at high power levels are the bellows in the warm coaxial line. At the power of $50 \mathrm{~kW}$ the bellows temperature would reach $400 \mathrm{~K}$ on the outer conductor and $375 \mathrm{~K}$ on the inner conductor. This problem is solved in the new design by providing air cooling of both bellows of the warm coax line. For realizing the cooling of the outer conductor bellows, an additional edge-welded bellows unit is added to the design. It encloses the regular bellows and an air flow is established in the space between the two bellows. The general design of the coupler is shown in Figure 3.

The coupler has to deliver RF power to a superconducting cavity, i. e. it is a part of the cryogenic system. Table 2 shows the values of heat loads of a single coupler to the cryogenic system.

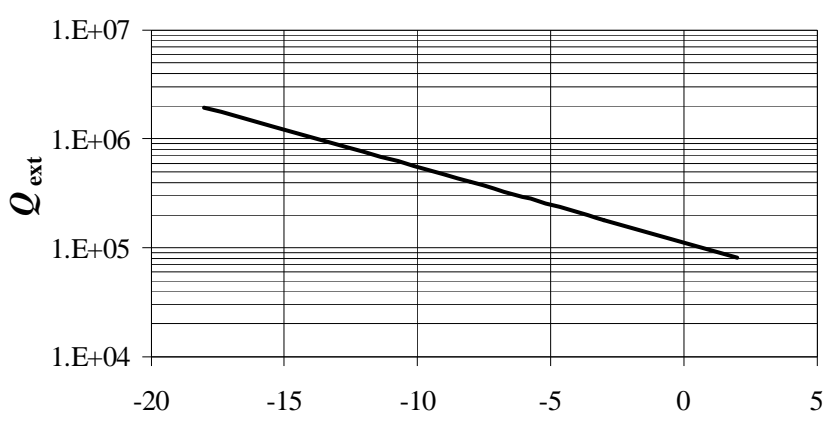

Antenna penetration depth, mm

Figure 2: Dependence of $Q_{\text {ext }}$ of a single coupler on the penetration of the antenna tip into the cavity beam pipe. The $Q_{\text {ext }}$ of a twin coupler is twice as low.

Table 2: Injector cavity coupler heat loads.

\begin{tabular}{|c|c|c|}
\hline & Static & At $50 \mathrm{~kW}(\mathrm{CW}, \mathrm{TW})$ \\
\hline To $1.8 \mathrm{~K}$ & $0.05 \mathrm{~W}$ & $0.2 \mathrm{~W}$ \\
\hline To $4.2 \mathrm{~K}$ & $0.30 \mathrm{~W}$ & $2.0 \mathrm{~W}$ \\
\hline To $70 \mathrm{~K}$ & $6.80 \mathrm{~W}$ & $31 \mathrm{~W}$ \\
\hline
\end{tabular}

\section{FIELDS SYMMETRY AND BEAM DYNAMICS}

The twin coupler design gives an excellent transverse field symmetry on the beam axis. There can be only residual transverse fields due to antennae position errors and errors of power and phase balance between two single couplers.

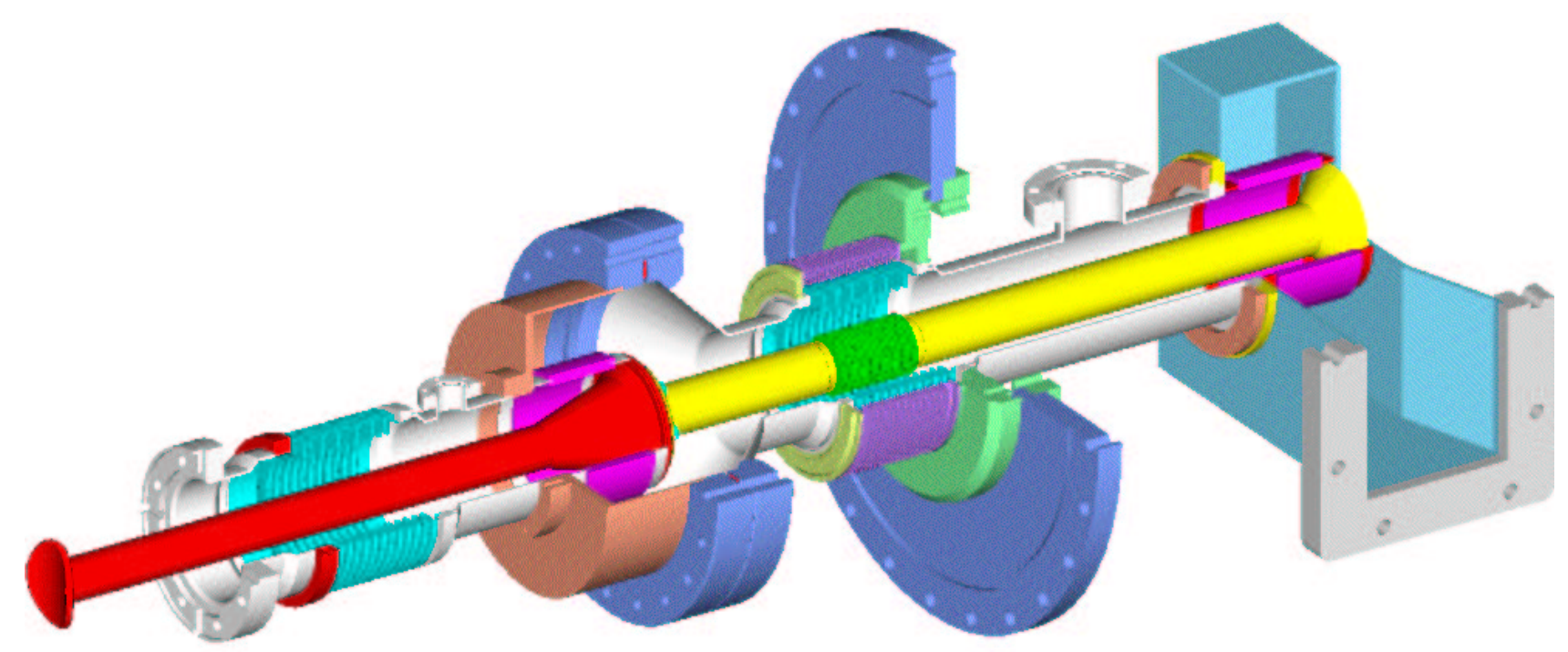

Figure 3: View of the injector cavity coupler. 
Figure 4 shows the distribution of transverse fields along the beam axis for $1 \mathrm{~mm}$ difference of antenna penetration depths of two couplers (for the strongest coupling where the response to position errors is maximal). The 3D computer code CST Microwave Studio ${ }^{\circledR}[11]$ was used for field calculations. The fields are normalized to the maximum accelerating field $E_{\mathrm{zm}}$ on the axis. Integrating the fields, one can calculate the transverse kick for different coupler errors [7], [8]. The results are summarized in Table 3 . For a comparison, the transverse kick of a single coupler is also presented in the table.

Table 3: Relative transverse kick (normalized to the maximum accelerating voltage) due to twin coupler errors.

\begin{tabular}{|l|l|c|}
\hline Error in: & $\begin{array}{c}\text { Error } \\
\text { value }\end{array}$ & $\begin{array}{c}\text { Transverse } \\
\text { kick }\end{array}$ \\
\hline Relative penetration depth & $1 \mathrm{~mm}$ & $8.0 \times 10^{-4}$ \\
\hline Relative phase & $1^{\circ}$ & $5.0 \times 10^{-4}$ \\
\hline Relative power & $1 \%$ & $4.5 \times 10^{-5}$ \\
\hline Single coupler & & $3.0 \times 10^{-3}$ \\
\hline
\end{tabular}

The influence of an injector cavity on beam dynamics was simulated using the 3D computer code ASTRA [12]. The results are shown in Table 4.

Table 4: Beam emittance growth due to RF focusing and kick in the injector cavity with a single coupler and with a twin coupler.

\begin{tabular}{|c|c|c|c|c|c|c|}
\hline & $\begin{array}{c}q \\
{[\mathrm{pC}]}\end{array}$ & $\begin{array}{c}V_{\mathrm{acc}} \\
{[\mathrm{MV}]}\end{array}$ & $\begin{array}{c}\varepsilon_{0} \\
{[\mu \mathrm{m}]}\end{array}$ & $\begin{array}{c}\sigma_{\mathrm{z}} \\
{[\mathrm{mm}]}\end{array}$ & $\begin{array}{c}\sigma_{\mathrm{x}} \\
{[\mathrm{mm}]}\end{array}$ & $\begin{array}{c}\text { emittance } \\
\text { growth }\end{array}$ \\
\hline \multirow{2}{*}{$\begin{array}{c}\text { single } \\
\text { input } \\
\text { coupler }\end{array}$} & 77 & 1 & 1.0 & 0.6 & 2.0 & $6 \%$ \\
\cline { 2 - 7 } & 77 & 3 & 1.0 & 0.6 & 0.9 & $3 \%$ \\
\hline \multirow{2}{*}{$\begin{array}{c}\text { twin } \\
\text { input } \\
\text { coupler }\end{array}$} & 8 & 3 & 0.1 & 0.6 & 0.6 & $16 \%$ \\
\cline { 2 - 7 } & 77 & 1 & 1.0 & 0.6 & 2.0 & $4 \%$ \\
\cline { 2 - 7 } & 8 & 1 & 0.1 & 0.6 & 0.6 & $4 \%$ \\
\hline
\end{tabular}

One can see from these estimates that coupler kick contribution is not important for nominal bunch charge of $77 \mathrm{pC}$ but becomes noticeable in the case of ultra-low $0.1 \mu \mathrm{m}$ emittances. For cavity with the twin coupler the emittance growth governs solely by RF focusing.

\section{CONCLUSION}

A preliminary design of the input coupler for the Cornell / JLab ERL injector cavity has been done. Based on the TTF III TESLA coupler design, it is developed for a much higher $\mathrm{CW}$ power operation. A twin coupler design has a very good field symmetry and meets stringent requirements of the ERL project.

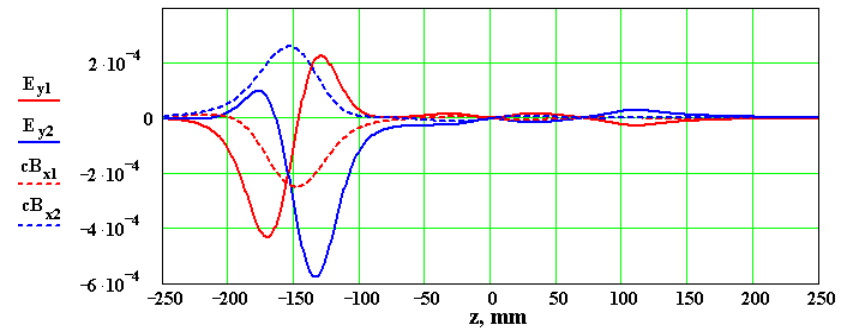

Figure 4: Normalized transverse fields on the axis of the injector cavity for a relative penetration depth error of $1 \mathrm{~mm}$. The coordinate $z=0$ corresponds to the cavity center. $E_{\mathrm{y} 1}, B_{\mathrm{x} 1}$ and $E_{\mathrm{y} 2}, B_{\mathrm{x} 2}$ were calculated respectively for shorted and open coupler.

\section{REFERENCES}

[1] S. M. Gruner and M. Tigner (editors). "Study for a Proposed Phase I Energy Recovery Linac (ERL) Synchrotron Light Source at Cornell University". CHESS Technical Memo 01-003, JLAB-ACT-0104, 2001.

[2] I. Bazarov, et al. "Phase I Energy Recovery Linac at Cornell University," Proc. of the 8th European Part. Accel. Conf., (Paris, France, 2002), p. 644.

[3] G. Hoffstaetter, et al. "The Cornell ERL Prototype Project". This Proceedings, report TOAC005.

[4] C. Sinclair and I. Bazarov. "High Brightness, High Current Injector Design for the Cornell ERL Prototype". This Proceedings, report WPAB013.

[5] M. Liepe, et al. "Overview of the Cornell ERL Injector Cryomodule". This Proceedings, report TPAB052.

[6] S. Belomestnykh, et al. "High Average Power Fundamental Input Couplers for the Cornell University ERL: Requirements, Design Challenges and First Ideas". ERL 02-8, Cornell University, 2002.

[7] V. Shemelin, S. Belomestnykh, and H. Padamsee. "Low-Kick Twin-Coaxial and Waveguide-Coaxial Couplers for ERL". SRF 021028-08, Cornell University, 2002.

[8] V. Shemelin, et al. "Dipole-Mode-Free and KickFree 2-Cell Cavity for the SC ERL Injector". This Proceedings, report WPAB012.

[9] B. Dwersteg, et al. "TESLA RF Power Couplers Development at DESY". Proc. of the $10^{\text {th }}$ Workshop on RF Superconductivity, Tsukuba, Japan, 2001.

[10] B. Dwersteg. "Couplers for Superconducting Cavities at $1.3 \mathrm{GHz}$ High CW Power," presented at the Workshop on $1.3 \mathrm{GHz}$ Couplers for $\mathrm{CW}$ Operation at Power Levels between 10 and 100 kW, ACCEL Instruments $\mathrm{GmbH}$, Bergisch Gladbach, Germany, April 9, 2002.

[11] CST GmbH, Darmstadt, Germany.

[12] P. Piot. Private communication. 